Original Article

\title{
MONTHLY CHANGES IN HONEY BEE FOREWINGS ESTIMATED USING GEOMETRIC MORPHOMETRICS
}

\author{
Anna Janczyk \\ Adam Tofilski* \\ University of Agriculture in Krakow, Poland \\ *corresponding author: rotofils@cyf-kr.edu.pl \\ Received: 17 June 2020; accepted: 27 October 2020
}

\begin{abstract}
Honey bee (Apis mellifera) wing measurements are often used to discriminate lineages and subspecies. The precision and repeatability of the measurements depends on various factors, including seasonal variation, and differences between left and right wings. The seasonal variation of the cubital index, which is the proportion of two vein lengths, has been investigated, but subspecies can be identified through geometric morphometrics. This method allows both wing size and shape to be determined and analyzed separately. We studied changes in the wing size and shape in consecutive months between June and September as well as the differences between the left and right wings. We found that wing size differed significantly among colonies, months and body sides, but shape differed significantly only among colonies and months but not among body sides. There was also a complicated pattern of interactions between various factors. The seasonal differences in wing shape were much smaller than the differences among colonies and their influence on identification of honey bee lineages was relatively small.
\end{abstract}

Keywords: Apis mellifera, forewing, geometric morphometrics, shape, size

\section{INTRODUCTION}

The identification of honey bee (Apis mellifera) subspecies and lineages is often based on wing venation. It had been based on the cubital index (Alpatov, 1948; Goetze, 1959), which is a proportion of two vein lengths, but later the angles between wing vein intersections were included in the measurements (DuPraw, 1965). Recently, the wings have been described according to the coordinates of landmarks located in forewing vein intersections (Francoy et al., 2008; Tofilski, 2008; Barour \& Baylac, 2016; Ángel-Beamonte et al., 2018; Bustamante et al., 2020; Dukku \& Danailu, 2020; ). This method, called geometric morphometrics, has proven to be effective in the discrimination of honey bee subspecies (Gerula et al., 2009) and lineages (Nawrocka et al., 2017). Geometric morphometrics provides the same (Tofilski, 2008) or even better (Rafie et al., 2014) discrimination in comparison to standard morphometry based on angles and the cubital index.

Most differences among honey bee subspecies are determined genetically (Węgrzynowicz et al., 2019), but honey bee wing venation is also known to be affected by multiple environmental factors including Varroa destructor infestation (Belaïd, 2010), temperature (Zhu et al., 2018), cell size (McMullan \& Brown, 2006) and food availability (Szentgyörgyi et al., 2016). There are also some small differences between the left and the right wing (Smith et al., 1997). Occasionally individuals have abnormal venation, for example with veins missing (Łopuch \& Tofilski, 2016). Honey bee wing venation can also be affected by seasonality; over the course of a year there are changes in outside temperature, food availability, food type, beekeeping practices, the prevalence of pathogens and parasites (Tentcheva et al., 2004). In consequence, there were found seasonal differences in susceptibility to agrochemicals (Meled et al., 1998 ) and the ability to learn (Ray \& Ferneyhough, 1997).

Seasonal variability of wing venation can affect the identification of honey bee subspecies. The cubital index has been shown to vary seasonally 
between 2\% (Gromisz, 1962) and 27\% (Nazzi, 1992) and also wing size expressed as wing width and length or vein lengths (Gromisz, 1962; Nazzi, 1992). A similar variation in wing size and shape was also found in $A$. cerana (Mattu $\&$ Verma, 1984). Those studies used the cubital index or angles between vein intersections to describe wing shape; however it is not clear how seasonal variation affects the identification of honey bees based on geometric morphometrics, where the coordinates of nineteen points are used to describe the wing shape. Such information is important to estimate the precision of the identification and its susceptibility to seasonal changes.

The aim of this study was to investigate how seasonal changes in wing venation affect the identification of honey bee lineages based on the methods of geometric morphometrics. Moreover, results of the identification based on the left and right wings were compared. Improved knowledge of the seasonal variation of forewing venation can help to assess the precision of the measurements and their interpretation.

\section{MATERIAL AND METHODS}

In this study, four colonies located in Garlica Murowana, Poland (latitude and longitude: 50.14, 19.93) were used. All colonies were under normal beekeeping practices involving inspections and honey harvesting. The investigated colonies were not obtained from honey bee queen breeders but were randomly chosen among managed colonies used for beekeeping. None of the colonies showed any symptoms of diseases other than Varroa mite infestation, which was mild because all were treated with acaricide at the end of previous season. In all colonies, comb foundation was used from the same manufacturer. The combs were not older than one year. Callow workers were collected over four consecutive months: June 3, July 4, August 3 and September 6. We recognized the workers as newly emerged by their characteristic color, general appearance, and behavior. The workers were kept in cages for one day until their cuticle was completely hardened. Every month twenty workers were collected from every colony, and in total 320 workers were analyzed. We report here the month of emergence even though most of the larval development occurred in the preceding month.

Both left and right forewings were dissected and mounted in diapositive frames (Rowi 260) between two pieces of glass. They were scanned using a Nikon SUPER COOLSCAN 5000 ED scanner equipped with a Nikon SF-210 slide feeder. The resolution of the images was 4000 dots per inch (image size: $5782 \times 3946$ pixels). In the forewing images, nineteen characteristic points called homologous landmarks were marked (Fig. 1, for details see Nawrocka et al., 2017). All the landmarks corresponded to type I landmarks (sensu Bookstein 1991) except for landmark 19 which was a type III. The landmarks were aligned using the Generalized Procrustes Analysis (Dryden \& Mardia, 1998) in MorphoJ v. 1.06c software (Klingenberg, 2011). Both the left and right forewings were measured in this way. The aligned coordinates of the landmarks were used to describe the wing shape. The natural logarithm of centroid size (CS) was used to describe the wing size. Differences in wing shape were measured as the Procrustes distance.

Differences in wing size were analyzed with a three-way analysis of variance (ANOVA) with colony, month and body side as independent variables (factors). Differences in wing shape were analyzed with a three-way multivariate analysis of covariance (MANCOVA) with CS used as covariate and the same independent

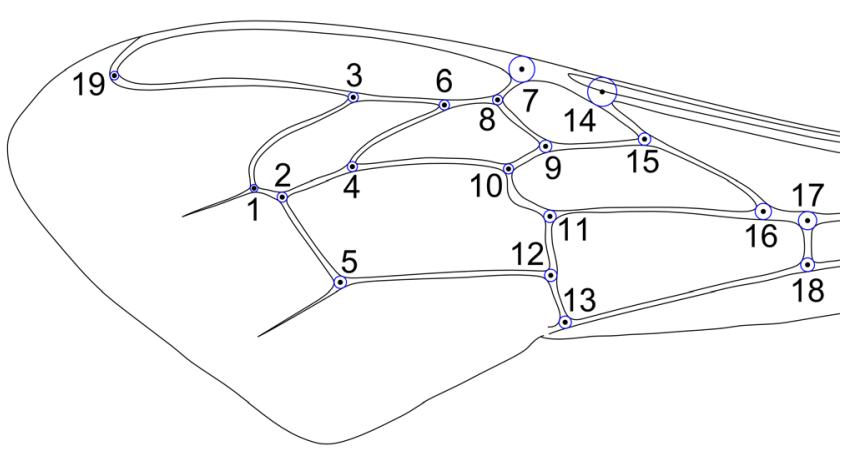

Fig. 1. Schematic of forewing of honey bee worker with landmarks marked as black dots and numbers. 
variables as in the previous analysis. In order to test how differences between months and body sides affect identification, we used Identifly software. Every colony was classified as one of the four lineages of the honey bee: $A, C, M$ and 0 . Lineages were identified instead of subspecies because the available reference samples were large and would provide more reliable results.

\section{RESULTS}

Forewing size (measured by CS) differed significantly among colonies, months and sides (Tab. 1). The largest differences in forewing size were between colonies and the means of the CS $( \pm S D)$ in our analyzed colonies $(A, B, C$ and $D)$ were $6.469 \pm 0.016,6.490 \pm 0.019,6.488 \pm 0.011$ and 6.479 \pm 0.017 , respectively. CS differed less between the months June, July, August and September and was $6.478 \pm 0.017,6.486 \pm 0.017$, $6.484 \pm 0.018,6.478 \pm 0.018$, respectively. The smallest differences in forewing size were observed between sides, and the mean CS of the left and right forewing was $6.480 \pm 0.018$ and $6.483 \pm 0.018$, respectively. There was also significant interaction between the factors of colony and month (Tab. 1), which indicated that the pattern of forewing size changes in consecutive months differed among colonies. In two colonies, maximum forewing size was achieved in July and in the other two in August (Fig. 2). Other interactions were not significant (Tab. 1). The multivariate analysis of covariance revealed that there was a significant allometric

Differences in wing size analyzed by three way analysis of variance

Table 1.

\begin{tabular}{ccccc}
\hline Effect & df & MS & $F$ & $P$ \\
\hline colony & 3 & 5894 & 58 & 0.000000 \\
month & 3 & 1084 & 11 & 0.000001 \\
side & 1 & 421 & 4 & 0.043060 \\
colony*month & 9 & 755 & 7 & 0.000000 \\
coony*side & 3 & 16 & 0 & 0.926473 \\
month*side & 3 & 6 & 0 & 0.983432 \\
colony*month*side & 9 & 14 & 0 & 0.998740 \\
\hline
\end{tabular}

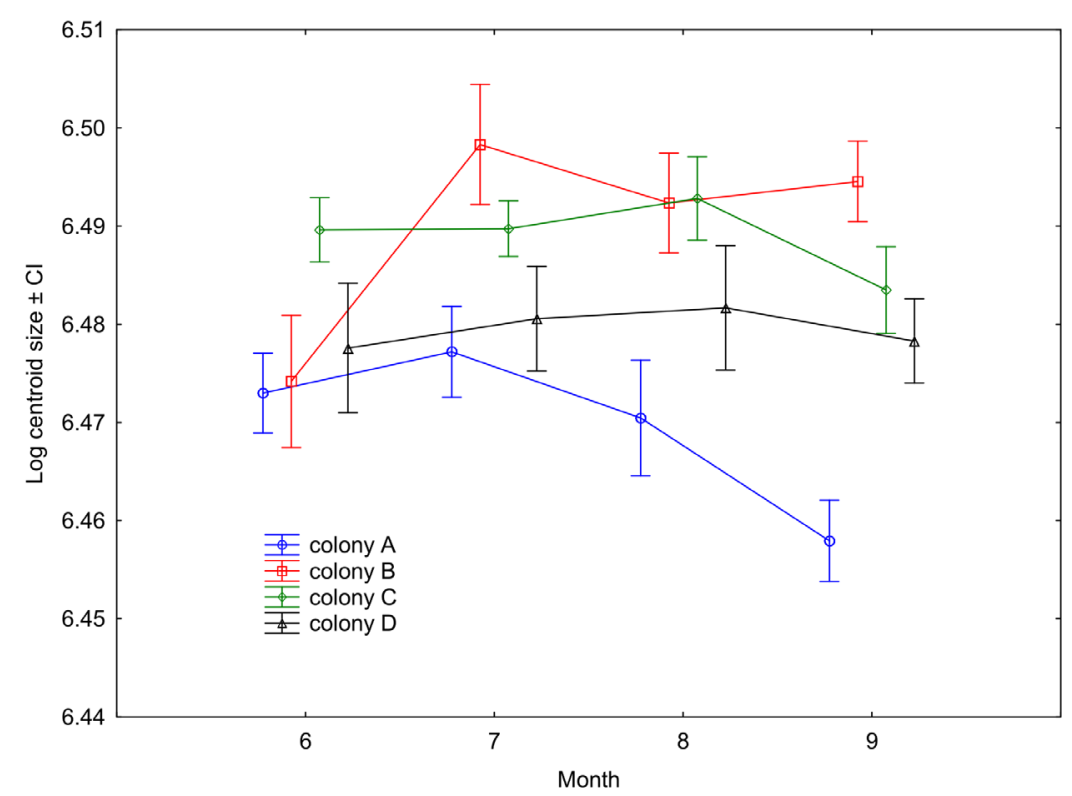

Fig. 2. Mean logarithm of centroid size $\pm 95 \%$ confidence intervals (CI) in four honey bee colonies during four months. 
Table 2 . Differences in wing shape analyzed by multivariate analysis of covariance (MANCOVA) with wing size used as covariate

\begin{tabular}{|c|c|c|c|}
\hline Effect & Wilks $\Lambda$ & $\mathrm{F}$ & $p$ \\
\hline colony & 0.562513 & 3.273041 & 0.000000 \\
\hline month & 0.729034 & 1.719851 & 0.000020 \\
\hline side & 0.979761 & 0.319570 & 0.999931 \\
\hline size & 0.738690 & 5.472685 & 0.000000 \\
\hline colony ${ }^{\star}$ month & 0.392991 & 1.702865 & 0.000000 \\
\hline colony*side & 0.900845 & 0.548305 & 0.999919 \\
\hline month*side & 0.908418 & 0.503640 & 0.999990 \\
\hline colony*size & 0.570564 & 3.184397 & 0.000000 \\
\hline month*size & 0.729804 & 1.713796 & 0.000023 \\
\hline side*size & 0.979607 & 0.322057 & 0.999925 \\
\hline colony*month ${ }^{\star}$ side & 0.728981 & 0.556043 & 1.000000 \\
\hline colonymonth^size & 0.393136 & 1.702155 & 0.000000 \\
\hline colony*side*size & 0.901142 & 0.546541 & 0.999925 \\
\hline month*side*size & 0.908748 & 0.501705 & 0.999991 \\
\hline colony*month^side*size & 0.729055 & 0.555861 & 1.000000 \\
\hline
\end{tabular}

relationship between wing shape and size (Tab. 2, effect of size). The percent of the wing shape variance explained by size for combined data was $2.11 \%$. Wing shape differed among colonies and months but not between sides (Tab. 2). The largest difference in wing shape, measured by the Procrustes distance, was 0.0190 and occurred between colonies $C$ and $D$. The largest difference in wing shape between two months was 0.0062 and occurred between August and September. The difference in shape between left and right forewings was 0.0027. There was a complicated pattern of interaction between colony, month and centroid size (Tab. Z).

Using the wing shape of workers from different months for the identification of honey bee lineage resulted in some varied results (Fig. 3A). However, this variation did not affect the final conclusion of the identification. In all consecutive months, colonies $A, B, C$ and $D$ were classified as lineages $A, C, A$ and 0 , respectively. Variation in the results related to the left or right forewing was smaller (Fig. 3B) and did not affect the lineage identification, which was the same as in the case of different months.

\section{DISCUSSION}

The results presented here show that the statistically significant differences among forewings collected in different months are relatively small in comparison to differences among colonies. In some circumstances, when a colony is a hybrid of two subspecies, those small differences can lead to different conclusions. This should be taken into account when the results of identification are interpreted. Not only should it be recorded which reference group is most similar to the analyzed sample, but also the similarity to different groups should be analyzed. If the probability of identification is similar in the case of two or more groups, then another measurement performed at a different time can lead to the conclusion that the most similar group is different.

All the investigated colonies should be considered as hybrids, but they were classified to the most similar lineage. Only one colony was most similar to lineage $C$, which is native to the study location. Other colonies were most similar either to lineage $A$ or 0 . The presence of non 

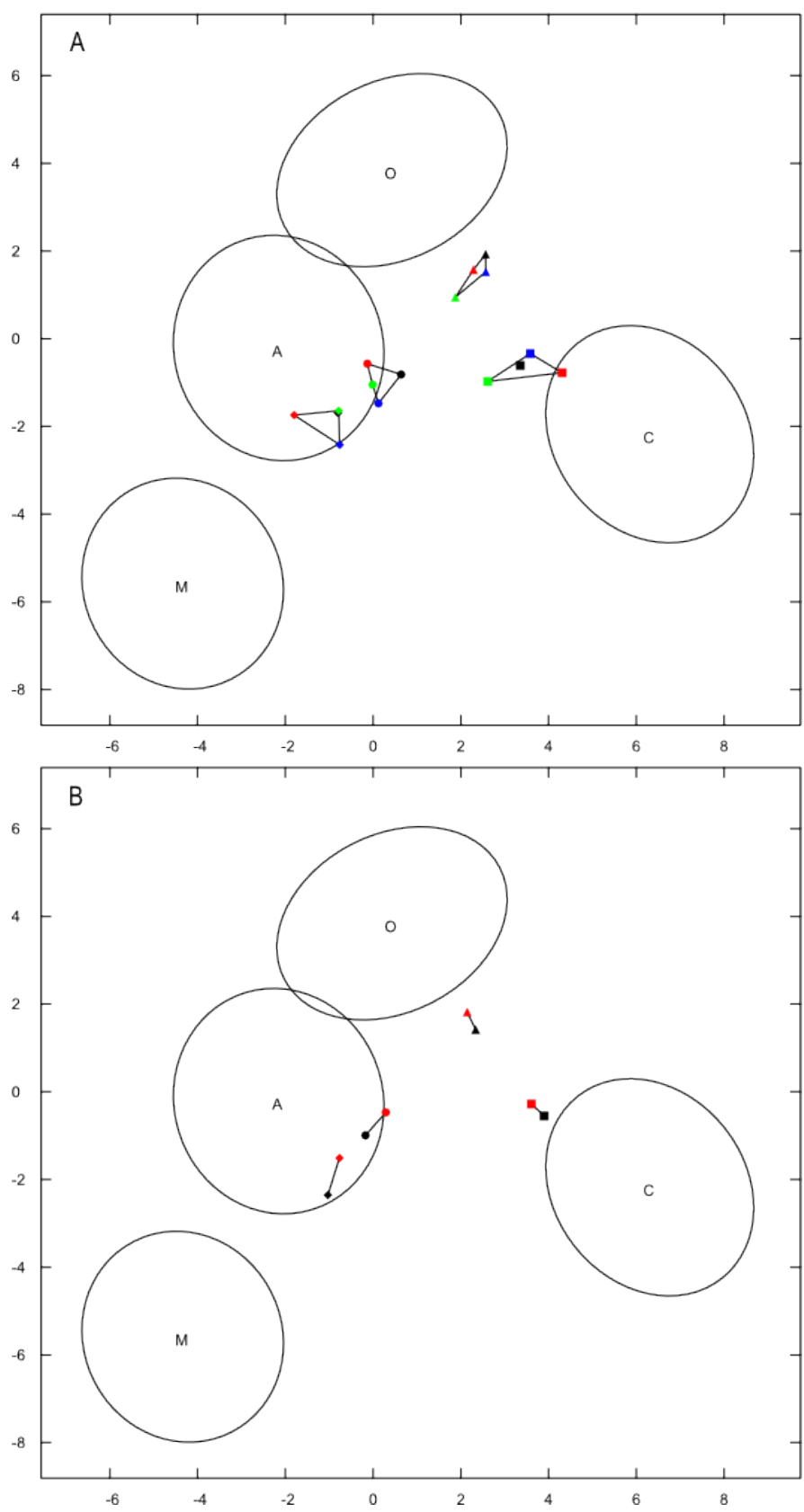

Fig. 3. Discrimination of honey bee lineages based on the first two canonical variates obtained with Identifly software. Colonies A, B, C and D were indicated with circles, squares, diamonds and triangles, respectively. In graph A, June, July, August and September were indicated with blue, red, green and black, respectively. In graph B, the left and right body sides were indicated with red and black, respectively.

native bees is related to the importation of genetic material by honey bee queen breeders and massive production of queens. Bees from lineage $A$ were used to obtain hybrids distributed as Buckfast breeding line. The presence of lineage 0 is probably related to the import of $A$. m. caucasica.

The monthly variation of wing shape was significant, but it occurred in an unpredictable way between colonies and months. This unpredictability was possibly related to hybridization and different genetic background of the investigated colonies. The monthly variation among related colonies from the same subspecies could be more consistent. The workers of our hybridized colonies from early summer cannot be predicted to be more similar to any of the lineages than workers from later summer. The monthly variation makes identification less precise, but it is difficult to recommend in which month the samples should be collected. In contrast to seasonal variation, there were no 
significant differences in wing shape between the left and right forewings.

The seasonal variation of forewing shape observed here is consistent to some degree with earlier studies, which were based on the cubital index or venation angles. Gromisz (1962) determined that the cubital index did not differ significantly between months, but Nazzi (1992) concluded that there were large and significant seasonal differences. In the latter study, the cubital index variation was particularly large earlier in the season. In all of those studies, the value of the cubital index varied unpredictably over the course of the year. The large variation of the indexes used in traditional morphometry suggests that geometric morphometrics based on landmarks is more suitable for the description of wing shape.

If differences among subspecies are relatively large, for example when they belong to different lineages, then they can be successfully discriminated using wing shape (Francoy et al., 2008; Tofilski, 2008; Barour \& Baylac, 2016). In those cases, seasonal variation is less likely to affect the discrimination. However, if differences between subspecies are smaller their discrimination based on wing shape is less successful (Kandemir et al., 2011; Nawrocka et al., 2017) and seasonal variation can be an important factor.

In comparison to wing shape, the seasonal variation of wing size is more predictable. Although there are some differences between colonies (Fig. 2), the wing size tends to be largest in the middle of the summer. These results agree with those of an earlier study conducted by Gromisz (1962) in a similar climate. Nazzi (1992) conducted another study in a Mediterranean climate and reported that the wing size variation seemed to be different. The main factor affecting wing size is possibly food availability, which differs among locations and years. In the climatic conditions of this study site, vegetation starts to develop in March and April but most plants important as food sources flower in May and June. The availability of pollen and nectar gradually decreases in July, August and September. Another factor which could affect monthly variation of wing size is Varroa mite infestation. The colonies were treated at the end of the previous season and the population of mites probably increased during the experiment. Unfortunately, infestation of the investigated colonies was not monitored. An attempt to explain the observed variation of wings size can be difficult because different factors, including food availability and Varroa infestation (Nürnberger et al., 2019), are linked to one another.

Wing size is effected by the environmental factors more than shape, and therefore, using it for discrimination between subspecies or lineages may be risky, even if it increases slightly the success of the discrimination of a particular dataset (Barour \& Baylac, 2016). Moreover, there is a significant relationship between size and shape (Tab. 2, effect of size), and it is difficult to make the discrimination completely independent of size. Fortunately, the percentage of shape variance explained by size is relatively small.

We also found significant differences in wing size between the left and right body sides, which is often called directional asymmetry of wing size. This confirms earlier studies by Smith et al. (1997), Schneider et al. (2003) and Łopuch \& Tofilski (2016). In all cases, the right forewings were larger than the left ones, although the significance of the differences in size between body sides was small in comparison to differences between colonies.

The results presented here show that forewing shape and size are not only determined genetically but also depend on many environmental factors. Those factors should be taken into account when planning wing measurements and interpreting their results.

\section{ACKNOWLEDGMENTS}

We are grateful two anonymous reviewers for the helpful comments on an earlier version of the manuscript. We thank Lidia Kantor for help with conducting the experiment. The research was supported by Polish National Science Centre (NCN) grant number DEC-2013/10/E/ NZ9/00682. 


\section{J. APRC. SUL. UQL. 65 NOL. 12021}

\section{REFERENCES}

Alpatov, V. (1948). Porody medonosnoi pchely. Moskovskoje Obscestvo Ispytatielej Prirody.

Ángel-Beamonte, E., Martín-Ramos, P., Santolaria, P., Sales, E., Abizanda, J., Yániz, J. L. (2018). Automatic determination of landmark coordinates for honey bee forewing venation using a new MATLAB-based tool. Journal of Apicultural Research, 575), 605-610. https://doi.org/10.1080/00218839.2018.1501856

Barour, C., \& Baylac, M. (2016). Geometric morphometric discrimination of the three African honeybee subspecies Apis mellifera intermissa, A. m. sahariensis and $A$, m. capensis (Hymenoptera, Apidae): Fore wing and hind wing landmark configurations. Journal of Hymenoptera Research, 52, 61-70. https://doi. org/10.3897/jhr.52.8787

Belaïd, M. (2010). Effet du Varroa destructor sur la morphometrie alaire et sur les composants du systeme immunitaire de l'abeille ouvriere Apis mellifera intermissa. Lebanese Science Journal, 77(1), 8

Bookstein, F. L. (1991). Morphometric Tools for Landmark Data: Geometry and Biology. Cambridge University Press.

Bustamante, T., Baiser, B., Ellis, J. D. (2020). Comparing classical and geometric morphometric methods to discriminate between the South African honey bee subspecies Apis mellifera scutellata and Apis mellifera capensis (Hymenoptera: Apidae). Apidologie, 57(1), 123-136. https://doi.org/10.1007/s13592019-00651-6

Dryden, I. L., \& Mardia, K. V. (1998). Statistical shape analysis (Vol. 4). J. Wiley Chichester. https://pdfs.semanticscholar.org/6ba2/73a7cfa282f73423110d0 0a5d20ad36766el.pdf

Dukku, U. H., \& Danailu, G. (2020). An appraisal of subspecific classification of Apis mellifera L. in parts of West and Central Africa through landmark-based geometric morphometric analysis of forewings. Journal of Apicultural Research, 59(4), 722-729. https:// doi.org/10.1080/00218839.2019.1696009
DuPraw, E. J. (1965). The recognition and handling of honeybee specimens in non-Linnean taxonomy. Journal of Apicultural Research, 4(2), 71-84.

Francoy, T. M., Wittmann, D., Drauschke, M., Müller, S., Steinhage, V., Bezerra-Laure, M. A., De Jong, D., Gonçalves, L. S. (2008). Identification of Africanized honey bees through wing morphometrics: Two fast and efficient procedures. Apidologie, 39(5), 488494. https://doi.org/10.1051/apido:2008028

Gerula, D., Tofilski, A., Węgrzynowicz, P., Skowronek, W. (2009). Computer-assisted discrimination of honey bee subspecies used for breeding in Poland. Journal of Apicultural Science, 53(2), 105-114.

Goetze, G. (1959). Die Bedeutung des Flügelgeaders für züchterische Beuerteilung der Honigbiene. Zeitschrift Für Bienenforschung, 4, 141-148.

Gromisz, M. (1962). Seasonal variation of wing measurements and cubital index in honeybees [in Polish]. Pszczelnicze Zeszyty Naukowe, 6(3), 113-120.

Kandemir, I., Özkan, A., Fuchs, S. (2011). Reevaluation of honeybee (Apis mellifera) microtaxonomy: A geometric morphometric approach. Apidologie, 4ح(5), 618-627. DOl: 10.1007/s13592-011-0063-3

Klingenberg, C. P. (2011). Morpho): An integrated software package for geometric morphometrics. Molecular Ecology Resources, 17(2), 353-357. https://doi.org/10.1111/j.1755-0998.2010.02924.x

Łopuch, S., \& Tofilski, A. (2016). The relationship between asymmetry, size and unusual venation in honey bees (Apis mellifera). Bulletin of Entomological Research, 106(3), 304-313. https://doi.org/10.1017/ S0007485315000784

Mattu, V. K., \& Verma, L. R. (1984). Morphometric studies on the indian honeybee, Apis cerana indica F. Effect of seasonal variations. Apidologie, 15(1), 6373. https://doi.org/10.1051/apido:19840106

McMullan, J. B., \& Brown, M. J. (2006). The influence of small-cell brood combs on the morphometry of 


\section{_ JAMCZYK ET HL. _ Monthly changes in honey bee forewings}

honeybees (Apis mellifera). Apidologie, 376), 665672. https://doi.org/10.1051/apido:2006041

Meled, M., Thrasyvoulou, A., Belzunces, L. P. (1998). Seasonal variations in susceptibility of Apis me/lifera to the synergistic action of prochloraz and deltamethrin. Environmental Toxicology and Chemistry, 1712), 2517-2520. https://doi.org/10.1002/ etc.5620171220

Nawrocka, A., Kandemir, I., Fuchs, S., Tofilski, A. (2017). Computer software for identification of honey bee subspecies and evolutionary lineages. Apidologie, 49(2), 172-184. https://doi.org/10.1007/s13592-0170538-y

Nazzi, F. (1992). Fluctuation of forewing characters in hybrid honey bees from northeastern Italy. Journal of Apicultural Research, 37(1), 27-31. https://doi.org/ 10.1080/00218839.1992.11101257

Nürnberger, F., Härtel, S., Steffan-Dewenter, I. (2019). Seasonal timing in honey bee colonies: Phenology shifts affect honey stores and varroa infestation levels. Oecologia, 189(4), 1121-1131. https://doi. org/10.1007/s00442-019-04377-1

Rafie, J. N., Mohamadi, R., Teimory, H. (2014). Comparison of two morphometrics methods for discriminating of honey bee (Apis mellifera meda Sk.) populations in Iran. International Journal of Zoology and Research, 4(3), 61-70.

Ray, S., \& Ferneyhough, B. (1997). Seasonal variation of proboscis extension reflex conditioning in the honey bee (Apis mellifera). Journal of Apicultural Research, 36(2), 108-110. https://doi.org/10.1080/0 0218839.1997 .11100936

Schneider, S. S., Leamy, L. J., Lewis, L. A., DeGrandi Hoffman, G. (2003). The influence of hybridization between African and European honeybees, Apis mellifera, on asymmetries in wing size and shape. Evolution, 5710), 2350-2364. https://doi. org/10.1111/j.0014-3820.2003.tb00247.x
Smith, D. R., Crespi, B. J., Bookstein, F. L. (1997). Fluctuating asymmetry in the honey bee, Apis mellifera. Effects of ploidy and hybridization. Journal of Evolutionary Biology, 10(4), 551-574. https://doi. org/10.1046/j.1420-9101.1997.10040551.x

Szentgyörgyi, H., Czekońska, K., Tofilski, A. (2016). Influence of pollen deprivation on the fore wing asymmetry of honeybee workers and drones. Apidologie, 475), 653-662. https://doi.org/10.1007/ s13592-015-0415-5

Tentcheva, D., Gauthier, L., Zappulla, N., Dainat, B., Cousserans, F., Colin, M. E., Bergoin, M. (2004). Prevalence and seasonal variations of six bee viruses in Apis melliferaL. and Varroa destructormite populations in France. Applied and Environmental Microbiology, 70(12), 7185-7191. https://doi. org/10.1128/AEM.70.12.7185-7191.2004

Tofilski, A. (2008). Using geometric morphometrics and standard morphometry to discriminate three honeybee subspecies. Apidologie, 39(5), 558-563. https://doi.org/10.1051/apido:2008037

Węgrzynowicz, P., Gerula, D., Tofilski, A., Panasiuk, B., Bieńkowska, M. (2019). Maternal inheritance in hybrids of three honey bee subspecies. Journal of Apicultural Science, 63(1), 131-138. https://doi. org/10.2478/jas-2019-0010

Zhu, X., Xu, X., Zhou, S., Wang, Q., Chen, L., Hao, Z." Zhou, B. (2018). Low temperature exposure $\left(20^{\circ} \mathrm{C}\right)$ during the sealed brood stage induces abnormal venation of honey bee wings. Journal of Apicultural Research, 573), 458-465. https://doi.org/10.1080/0 0218839.2017 .1412575 